\title{
Psicologia Escolar: Um Duplo Desafio
}

Resumo: A educação representa a capacidade de um povo organizar-se e construir seu futuro, portanto, não se realiza ao acaso, mas como consequência de um esforço expressivo. A Psicologia Escolar pretende facilitar o desenvolvimento humano, mas ainda permanece pouco conhecida. O sucesso no desempenho do psicólogo escolar exige uma imagem clara de seus principais propósitos, enfrentando um duplo desafio: ser aceito na escola (sem ter seu papel limitado na busca da promoção do desenvolvimento infantil) e ser apoiado na organização de atividades preventivas que afetam o curso do desenvolvimento da criança (envolvendo o desenvolvimento cognitivo, afetivo, social e físico e o enriquecimento da interação social da criança). Brevemente, o propósito deste estudo é focalizar de forma prática um campo mais eficiente, amplo e satisfatório para a Psicologia Escolar.

Palavras-chave: Psicologia Escolar, Educação, desenvolvimento infantil.

\section{Luiza Elena Leite Ribeiro do Valle}

Psicóloga com especialização em Psicologia Clínica e Psicopedagogia. Mestrado em Psicologia Escolar pela PUC Campinas. Professora da pós-graduação em Psicopedagogia na FUNDEG, em Guaxupé. Membro da Sociedade Brasileira de Neuropsicologia. Autora do livro "Cérebro e Aprendizagem: Um jeito diferente de viver".

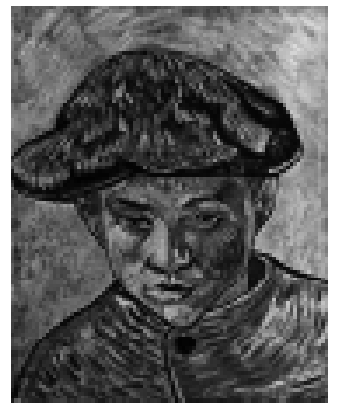

Abstract: Education is, at the same time, an indicator of the development of a country and a way to its progress. It represents a people's capacity to organize itself and to built its future, so, it doesn't happen randomly, but as a consequence of an expressive effort. School Psychology intends to facilitate human development, but is not fully understood yet. The successful school psychologist role requires a clear image of his primary purposes and faces a double challenge: be accepted in school (without restricting his role in order to promote child development) and be helped in organizing preventive activities that affect the course of child development (involving cognitive, affective, social and physical development and the enhancing of the child's social interaction). Briefly, the purpose of this study is to focus practical assumptions for an effective, broader and more satisfying role for school psychologists.

Key Words: School psychology, Education, child development.

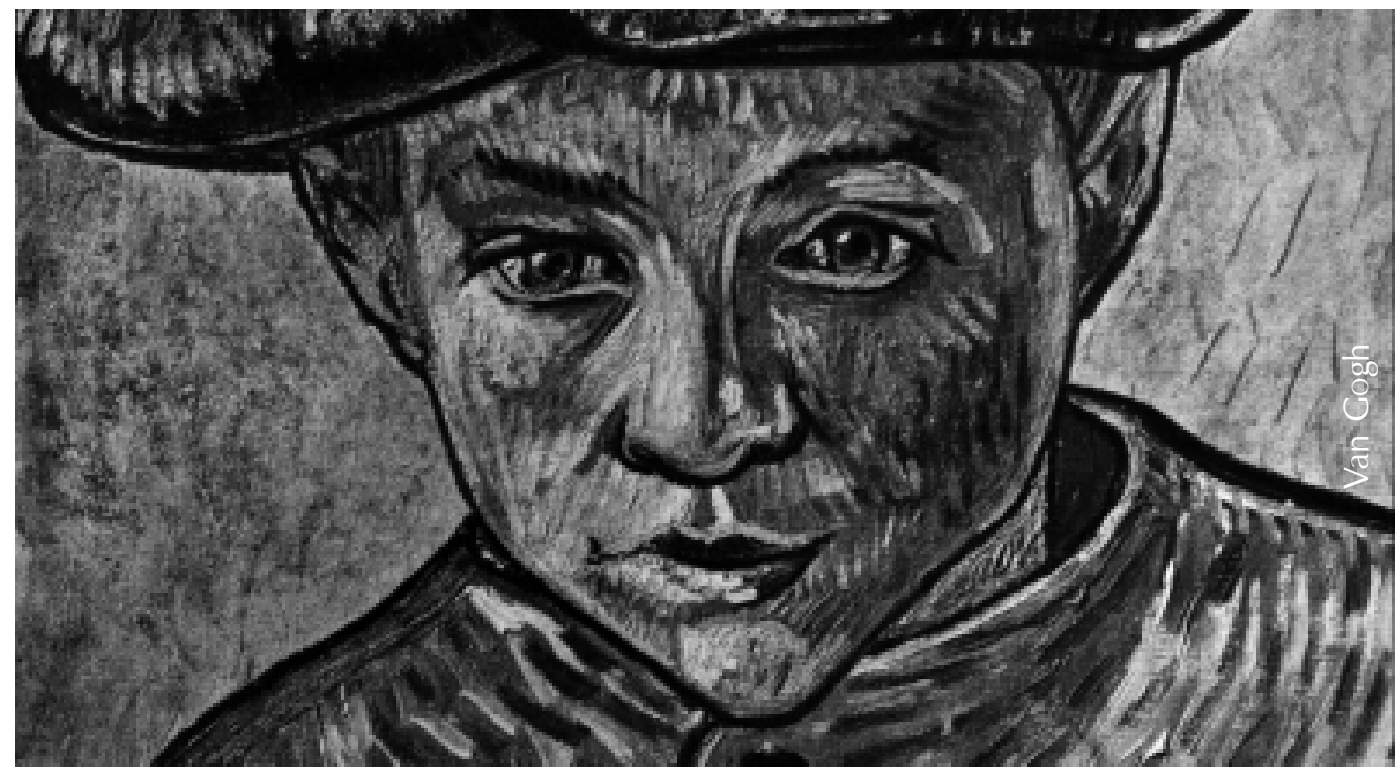

Os países mais desenvolvidos valorizam a Educação e aqueles que pretendem crescer precisam investir nela, superar deficiências e expandir sua participação no mundo globalizado. "A criança é o elo mais fraco e exposto da cadeia social. Nenhuma nação conseguiu progredir sem investir na infância. A viagem pelo conhecimento da infância é a viagem pela profundeza de uma nação. A situação da infância é um fiel espelho de nosso estágio de desenvolvimento econômico, político e social" (Dimenstein,1994, p.
8-9). O desenvolvimento psicossocial é o estudo indispensável para a formulação de estratégias eficazes que permitam transcender nossa realidade educacional, da qual o psicólogo não pode se alienar. Este estudo teórico preocupa-se com a reflexão indispensável à mudança de paradigmas que, no momento, não garantem campo de trabalho ao psicólogo escolar, apesar da evidente demanda. O psicólogo escolar luta pela compreensão social de sua função, que esbarra em dois desafios fundamentais: 
Sua inclusão na escola, para que seu trabalho não termine distorcido ou limitado no campo competitivo que envolve a afirmação de papéis de poder. Sua participação, com o corpo docente, em programas de intervenção pode permitir que, juntos, promovam o desenvolvimento infantil, de forma que Psicologia e Pedagogia se complementem, alcançando os objetivos idealizados.

Sua atuação preventiva, mais ampla, envolvendo a escola e a família, que precisam valorizar e compreender a necessidade de sua participação, não apenas remediativa ou voltada para a clínica, portanto, delimitando uma área especial da Psicologia que diferencie seu papel.

Entre os integrantes do EFA (Education for All, Tailândia, 1990), o Brasil foi um dos países que apresentaram alta taxa de analfabetismo e, "mesmo avançando muito nos últimos 10 anos, ainda está longe de onde precisamos chegar", conforme afirmação do Ministro de Educação, no Relatório Brasileiro EFA, em 2/02/2000. A situação escolar brasileira exige mudanças e muito esforço tem sido feito no sentido de diminuir a defasagem existente nas diversas regióes que representam nosso imenso território, mas, mesmo conseguindo-se resultados positivos, como o crescimento do número de matrículas e queda na distorção idade-série, houve uma tendência geral de rebaixamento dos resultados na avaliação dos testes de português e matemática, conforme conclui o Sistema Nacional de Avaliação da Educação Básica (SAEB, 2000) com os dados obtidos em pesquisa do ensino no Brasil através do censo educacional de 1999. Ainda, segundo a análise dos dados da pesquisa do SAEB, a cultura da repetência, já inexistente em países avançados, mas permanente aqui, leva pais e professores a responsabilizarem o aluno pelas eventuais deficiências em seu aprendizado, o que, ao invés de contribuir para a melhoria do desempenho do aluno, acaba por desmotivá-lo, podendo levar até mesmo à evasão escolar.

Muito tem sido feito para que a escola não se preste a selecionar os mais capazes e eliminar quem enfrenta dificuldade para aprender e, em vez disso, incorporar todos os alunos. A pesquisa educacional, nos últimos anos, tem procurado revelar aspectos dos bastidores da sala de aula e do funcionamento da escola, da atuação dos professores bem-sucedidos, dos processos que produzem à patologização da aprendizagem, de questões relativas à didática do professor, entre outros. A mobilização pelo desenvolvimento nacional precisa rever pontos negligenciados nessa luta. Para alterar radicalmente resultados negativos, há necessidade de um esforço social, principalmente por parte daquele a quem cabe o papel de especialista na problemática da escola, o psicólogo escolar, profissional imprescindível nesse momento e, contraditoriamente, pouco valorizado, sem campo de atuação em meio à vasta carência existente. Por que isso acontece?

O psicólogo escolar tem sua especialidade ainda pouco difundida. Apenas em 1990, com a formalização da Associação Brasileira de Psicologia Escolar e Educacional (ABRAPEE), houve possibilidade de fortalecimento desse campo de atuação no Brasil, conforme Pfromm Netto (1995) comenta: "O surgimento da ABRAPEE constituiu o coroamento dos esforços de todos quantos vinham se empenhando para dar uma posição de relevo à Psicologia Escolar em nosso meio para consolidar seu status de área de atuação, de investigação científica e de preparo profissional".

Numa perspectiva histórica da Psicologia Escolar no campo internacional, Batsche e Knoff (1995, p. 569570) enfatizam a tendência inicial da realização de diagnósticos classificatórios para encaminhamento de crianças a classes especiais, a partir de uma lei americana de 1975 (Public Law 94-142, apud Hightower, Johnson e Haffey, 1995) destinada a garantir a Educação para crianças com deficiências. A atuação do psicólogo escolar era, marcadamente, remediativa e focalizada no indivíduo, uma vez que a tendência psicometrista predominava, enquanto a prática da Psicologia se apoiava na aplicação de testes. Nessa tentativa de participar do corpo administrativo escolar, o psicólogo precisava limitar-se ao clientealuno, evitando interferir nas decisões docentes, como se o seu campo de estudo pudesse estar alheio à influência do ambiente. Entretanto, os problemas escolares como evasão, repetência, diferenças sociais, associados aos avanços da ciência, levaram o psicólogo a buscar um outro nível de contribuição eficaz. O modelo clínico passou a ser criticado na escola porque não questionava o sistema escolar (Andaló, 1984, p.43-46). Surgiu a preocupação em valorizar o processo de aprendizagem, priorizandose uma atuação mais abrangente e indireta, voltada para programas de treino para alunos com dificuldades, preparação e treinamento de professores, o que Almeida e Guzzo (1992, p.126) apontam como um salto marcante que resultou em "uma prática mais incisiva, presente e eficiente da Psicologia no contexto educativo". O psicólogo tornou-se requisitado como um solucionador de problemas, numa intervenção remediativa, porém com foco de atuação institucional.

A mudança para um enfoque preventivo decorre, segundo Almeida e Guzzo (1992), de movimentos da Educação e da Psicologia, rompendo com uma visão reducionista para lançar-se em objetivos amplos, onde a saúde mental passou a ter relevância, abarcando a responsabilidade pelo desen-volvimento integral dos educandos. A prevenção primária, embora mais difícil, procura mudar a
"A criança é o elo mais fraco e exposto da cadeia social. Nenhuma nação conseguiu progredir sem investir na infância. A viagem pelo conhecimento da infância é a viagem pela profundeza de uma nação. A situação da infância é um fiel espelho de nosso estágio de desenvolvimento econômico, político e social".

Dimenstein 
incidência de novos casos, intervindo proativamente, isto é, antes que os distúrbios ocorram (Knoff, 1995). São diversas as vantagens:

As competências podem ser aumentadas por meio da educação.

O treino pode auxiliar pessoas a desenvolver estratégias competitivas contra círculos viciosos de efeitos negativos ou situações estressantes de vida.

O ambiente pode ser modificado para reduzir ou conter circunstâncias prejudiciais.

Sistemas de apoio podem ser desenvolvidos mais amplamente.

A prática de ação dos psicólogos escolares se voltou para a escola fundamental (Witter et alii., 1992; Guzzo e Weschler, 1993) e o modelo clínico de intervenção continuou predominando, mas com a nova concepção do contexto educacional, acreditando-se na promoção de saúde, que passou a representar um recurso indispensável na expectativa de um desenvolvimento satisfatório.

A saúde é um processo complexo, qualitativo, que define o funcionamento completo do organismo, integrando de forma sistêmica o somático e o psicológico, formando uma unidade onde um atua sobre o outro. Além disso, o indivíduo é influenciado pelas interações pessoais e transações com o meio; por isso, para compreender o desenvolvimento emocional, é preciso ter em mente uma perspectiva biopsicossocial, de aspectos que interagem e se complementam no sujeito em formação. Não só o indivíduoé modelado pelo ambiente, como também o modela, e isso acontece para cada um de forma diferenciada, conforme descreve Rey (1993).

Ainda segundo Rey (1993), o desenvolvimento de um sólido sistema de interesses, de capacidade para decisões, da segurança em si mesmo, de uma autovalorização adequados são, entre outros indicadores, aspectos psicológicos indispensáveis a um desenvolvimento saudável. O processo de ensino deve desenvolver operações que estimulem a autonomia, a eliminação do medo, a segurança, a flexibilidade e o afã da busca, aspectos psicológicos que caracterizam uma personalidade sadia. A escola deve criar toda uma cultura de educandos para suas relações pessoais, e as crianças e jovens devem aprender a comunicar-se, com a estimulação do diálogo e da capacidade de se colocar no lugar do outro. A educação moral deve surgir através da reflexão de atividades e enfatizar a necessidade de ser autêntico, de que se formem pessoas capazes de assumir seus sentimentos e suas decisões, expressálos e defendê-los. O sucesso ou fracasso escolar da criança pode ser conceituado como o resultado da interação entre as características individuais do desenvolvimento, temperamento e motivação e específicos fatores ambientais encontrados em casa e na escola. Nesse contexto, qual a atuação do psicólogo escolar?

O psicólogo pode interferir nos fatores de proteção que podem ser desenvolvidos, voltando-se para os aspectos resilientes, que não perdem a estrutura em situação de estresse, olhando-se para o sucesso e não para o fracasso escolar. Os fatores orgânicos (distúrbios, dificuldades ou características individuais) e os fatores de estresse ( que incluem as experiências vividas em sua rede social e conseqüências da exposição aos conflitos ambientais) atingem, inevitavelmente, as pessoas até antes do nascimento, mas na fase pré-escolar ou escolar, quando o desenvolvimento biopsicossocial permite que a criança se insira na comunidade que a rodeia, o seu ajustamento social e saúde mental estarão tomando forma, determinando seu futuro. $O$ exposto não afetado (resiliente) tem fatores de proteção, que precisam ser analisados para que se possa fazer a prevenção de risco.

A prevenção se preocupa com grupos de alto risco (como nas escolas municipais que atendem a uma população de poucos recursos financeiros e culturais e com pouca proteção para lidar com colapsos individuais decorrentes de desemprego, vícios, problemas de saúde física ou mental, etc.) e preocupa-se em construir forças adaptativas através da educação para reduzir o estresse social, administrando-o (Fergays, 1982, pp. 209-210).

A idéia geral, atrás da promoção de saúde, é aumentar as habilidades, força ou adaptação de grupos determinados, isto é, focalizar os aspectos positivos de saúde ou ajustamento, conforme destaca Durlak (1998). Segundo ele, a prevenção primária é a intervenção na população normal , que se destina a prevenir a ocorrência de futuros problemas. A prevenção secundária é a intervenção na população com problemas iniciais para evitar o desenvolvimento de conseqüências mais sérias. Os fatores biológicos individuais estão envolvidos num processo holístico porque os comportamentos antissociais afetam as outras pessoas (Magnusson, Klinteberg \& Statin, 1994); dessa forma, as diferenças individuais precisam ser estudadas nos procedimentos preventivos (Eysenck \& Eysenck, 1985). Cabe à saúde mental positiva uma preocupação com o desenvolvimento da criança, especialmente levando-se em conta que "a formação da personalidade não ocorre como um processo espontâneo, mas organizado e orientado através de ações e atitudes concretas e, também, pode ser projetado e avaliado" (Rey, 1993). A maneira como cada um vê a si próprio depende também do modo como é visto pelos outros. O modo como os traços 
particulares de cada criança são recebidos pelo professor e pelos grupo em que se insere tem um grande impacto na formação de sua personalidade e sua auto-estima, já que sua identidade está em construção. Das experiências vividas, emerge o autoconceito que cada um tem de si, que vai delimitar sua competência em realizar tarefas e relacionar-se com as demais pessoas no meio social a que pertence.

Concordando com a importância do período escolar Gridley, Mucha e Hatfield (1995) afirmam que as pesquisas, em geral, podem trazer informações confiáveis para aumentar as chances de sucesso das crianças na escola, oferecendo aos pais e professores instrumentos para adequar experiências e planos curriculares às necessidades individuais. A essência da prevenção secundária é a identificação precoce de problemas e a intervenção antes que estes se tornem severos. Nos estágios iniciais, as intervenções podem encurtar a duração e a intensidade dos problemas, e quanto mais novas as crianças, maior flexibilidade psicológica, permitindo prognósticos mais favoráveis.

Ainda assim, a mudança de paradigmas na atuação do psicólogo escolar, minimizando atividades diretas (solução de problemas) e indiretas (aconselhamentos) relacionadas a tratamentos de reabilitação para desenvolver programas preventivos, focalizados em grupos em que os problemas estão apenas começando ou antes que ocorram, exige uma transformação nas expectativas de resultados imediatos em favor de procedimentos que possam fortalecer adequadamente os passos do programa, orientando as pessoas envolvidas no processo. Vários fatores se encontram presentes na inter-relação que ocorre na aprendizagem escolar, tanto na sala de aula (professor, metodologia, colegas) como na família, ou seja, influências extrínsecas ao aluno. O enfoque da atuação dos psicólogos escolares estaria muito mais próximo de uma atitude de interlocução junto aos educa-dores, discutindo e refletindo sobre as práticas educacionais na complexidade das relações que ocorrem no cotidiano escolar (Machado e Souza, 1997), devendo centralizar-se na competência estimuladora da pesquisa e incentivando com engenho e arte a gestação de sujeitos críticos e autocríticos, participantes e construtivos, como afirma Demo (1993, p. 103).

O psicólogo escolar deve, entre outras atribuições, investigar melhor o processo de construção do conhecimento, enfocando os tipos de conhecimento trazidos pela criança ao iniciar sua aprendizagem formal na escola e o que ocorre durante o processo, segundo Brambilla (1997). A conduta do professor e o seu perfil pessoal interferem e têm peso significativo para o desenvolvimento e o desempenho dos alunos (Andreazzi, Jacarini e Prigenzi - 1994). O psicólogo precisa, então, não apenas de conhecimentos psicológicos relacionados ao desenvolvimento infantil e às influências ambientais que o atingem, mas também voltados para a situação de aprendizagem e dos aspectos psicopedagógicos envolvidos. A atuação orientada para o grupo de alunos, não apenas para "alunos problemas", pode permitir que o professor perceba as crianças em seu jeito individual de ser, transpondo os muros da escola para conhecer sobre o aluno mais do que o currículo escolar determina e, dessa forma, melhorar o seu desempenho, envolvendo-se em seus interesses e realidades (Ribeiro do Valle, 2001). As melhores práticas na adoção de programas de prevenção ( Hightower, Johnson e Haffey, 1995) sugerem, inicialmente, a identificação das necessidades pela análise dos sistemas e programas e pela revisão de informações relevantes para que se estabeleça um relacionamento entre o psicólogo escolar e os

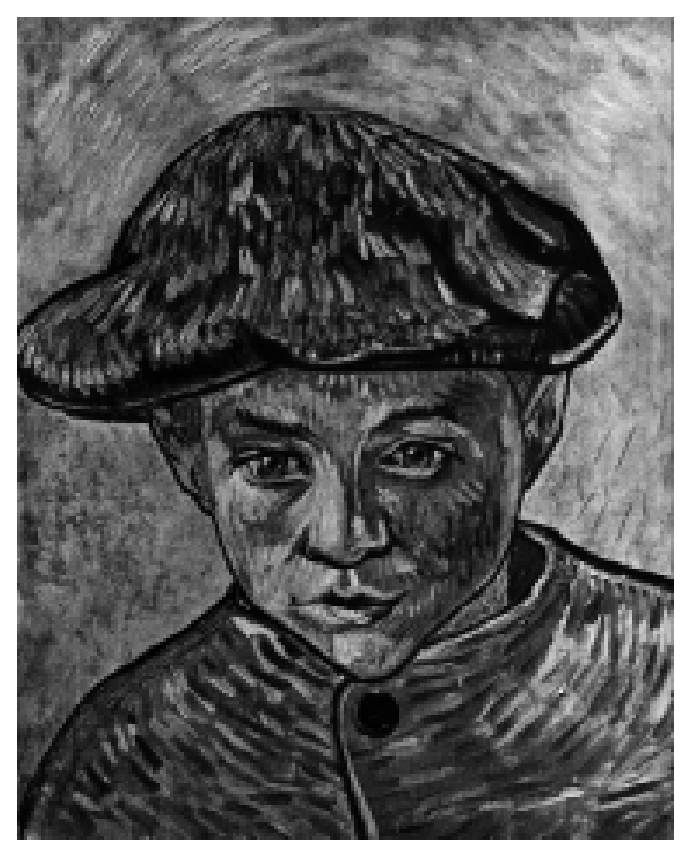

funcionários da escola, baseados em confiança, respeito, boa comunicação e compreensão, que contribua efetivamente para a introdução do procedimento. Cada passo deve ser cuidadosamente avaliado e compreendido tanto na introdução do programa quanto em sua manutenção e constante monitoração, garantindo eficácia. O problema da seriedade da atividade científica tornou-se crucial, segundo Morin (1998), e o psicólogo escolar, mais do que nunca, necessita de pesquisas como material indispensável de trabalho na promoção da saúde na escola e, é claro, na vida futura das crianças, não limitando seu campo de ação a "problemas de aprendizagem" que não podem ser recortados do restante do ambiente. E será suficiente que o psicólogo escolar atue sobre o ambiente da escola?
"O psicólogo precisa, então, não apenas de conhecimentos psicológicos relacionados ao desenvolvimento infantil e às influências ambientais que o atingem, mas também voltados para a situação de aprendizagem e dos aspectos psicopedagógicos envolvidos. A ałuação orientada para o grupo de alunos, não apenas para "alunos problemas", pode permitir que o professor perceba as crianças em seu jeito individual de ser, transpondo os muros da escola para conhecer sobre o aluno mais do que o currículo escolar determina e, dessa forma, melhorar o seu desempenho, envolvendo-se em seus interesses e realidades".

Ribeiro do Valle 
Além da escola, a família é um importante elemento na promoção da saúde porque nela se forma e se desenvolve a personalidade das crianças, sendo, também, o grupo social onde o homem expressa sua maior intimidade e espontaneidade, pois, como grupo, a família tem liberdade para definir seu próprio sistema de normas, estilo de vida etc., como afirma Rey (1993). As interações sociais que acontecem a uma criança desde o seu nascimento vão favorecer o processo de construção do conhecimento

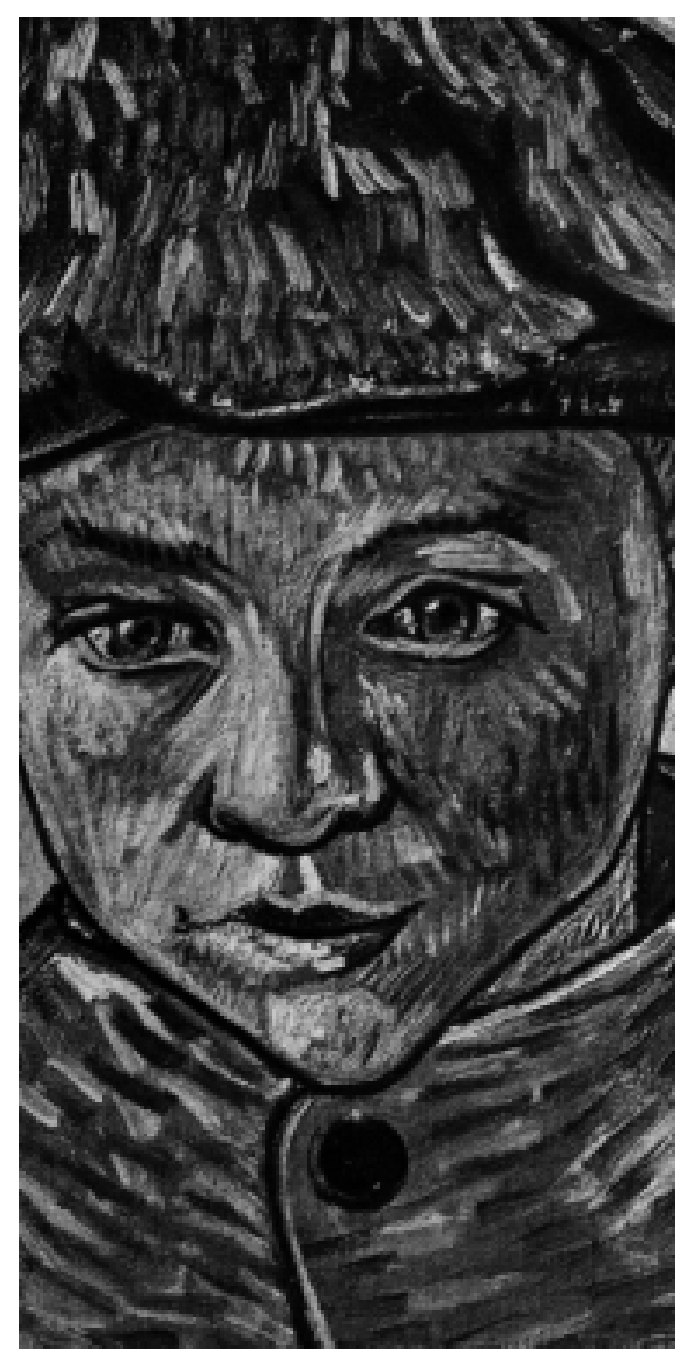

permitindo-lhe testar, reformular e organizar a realidade à sua volta, levando-a ao amadurecimento cognitivo e à formação de bases para novas aprendizagens.

Wise (1995) considera que a comunicação entre o psicólogo escolar e os pais é importante para que dividam informações sobre a criança: a impressão positiva dos pais sobre os cuidados que o filho recebe permite que possam seguir as recomendações, abrindo caminho para a cooperação e para uma melhor comunicação com os professores e demais membros da escola, permitindo-lhes redimensionar sua atuação em parceria na busca do aproveitamento escolar e no desenvolvimento dos filhos. O psicólogo escolar precisa ter conhecimentos sobre a influência da família no desempenho da criança para delinear as intervenções casa-escola em busca da inserção da criança nas relações éticas e morais que permeiam a sociedade que as envolve.

Para compreender melhor o significado, para a criança, do papel da família e da sua relação com a escola, pode-se recorrer a Bronfenbrenner (1996), que contribuiu com a visão ecológica no estudo do desenvolvimento humano, onde destaca o aspecto mutável, tanto do ambiente como do indivíduo. Ele define o desenvolvimento como uma mudança no modo como a pessoa percebe e atua sobre o ambiente, que, por sua vez, envolve uma correspondência mútua entre um conjunto de sistemas organizados nos seguintes níveis: Microssistema (um ambiente determinado), Exossistema (não contém a criança, mas a influencia), Macrossistema (o mais geral), Mesossistema ( relaciona dois ou mais ambientes do microssistema, como a relação entre família e escola).

Quatro tipos gerais de inter-relações citadas por Bronfenbrenner (1996, p. 161-162) podem ilustrar a relação família-escola, que são a participação multiambiente, ligação indireta, a comunicação interambiente e o conhecimento inter-ambiente. A criança vivencia o impacto entre os valores da escola e da família e deve atender às expectativas de cada um, ajustando o seu comportamento. O potencial desenvolvimental em um Mesossistema é aumentado se:

as exigências de papel nos diferentes ambientes são compatíveis;

os relacionamentos encorajam a confiança mútua e positiva;

permitem um consenso de objetivos e equilíbrio de poder favorável à pessoa.

Para que a família, escola ou qualquer outro sistema possa proporcionar desenvolvimento, depende da qualidade de relações estabelecidas com o outro Microssistema, de forma que haja comunicação conjunta e informação. A disponibilidade de ambientes apoiadores úteis permitirá o desempenho mais afetivo na educação, por isso o psicólogo escolar insere-se como mediador entre os Mesossistemas para que se complementem, favorecendo preventivamente a criança. O potencial desenvolvimental de um ambiente aumenta em função do número de vínculos apoiadores e, "entre esses sistemas, o familiar é o que adquire o papel mais relevante no que se refere à educação e assim, na atualidade, vê-se a escola e a família em inter-relação contínua" (Bassedas e colaboradores, 1996, p. 26). 
Há necessidade de se compreender o contexto do desenvolvimento infantil, com sensibilidade para as características típicas ou atípicas que ocorrem indiferentes às variáveis de idade, sexo, cultura etc. interpretando os dados a partir dessa perspectiva. Em um estudo realizado sobre um serviço municipal em Poços de Caldas, criado em 1992, pioneiro no Brasil no atendimento multidisciplinar integrado a crianças com dificuldades escolares (Cemada), através de uma equipe de saúde especializada em aprendizagem (neurologista, assistente social, 3 psicólogos, 3 fonoaudiólogos e 1 pedagogo) que atuam em interação com as famílias e escolas visando à solução dos problemas, pôde-se chegar a conclusões interessantes (Ribeiro do Valle, 2000). Foram pesquisadas 159 crianças (46 meninas e 113 meninos) entre 3 e 14 anos de idade. Todas as crianças examinadas apresentavam queixa de dificuldade escolar, sendo repetentes ou não, mas com problemas relacionados à alfabetização ou a aspectos anteriores a essa aquisição. Os dados foram coletados do livro de registros do Cemada, de março de 1999 a março de 2000, onde constam os resultados dos exames realizados por cada membro da equipe e o procedimento recomendado. $\bigcirc$ número de crianças encaminhadas pelas escolas com problemas no aprendizado mostrou-se bem maior com relação ao sexo masculino: (29\% de meninas, $71 \%$ de meninos). De acordo com os resultados dos exames neurológicos, o número de distúrbios orgânicos observados não se apresentou muito alto (27 crianças dos 159 encaminhamentos). Verificouse uma grande incidência de dificuldades referentes ao amadurecimento neuro-psicomotor, mas estas, além de obedecer a um ritmo específico de criança para criança, ainda sofrem influência da estimulação ambiental (93 no total). Guzzo (1990), Marchesi e Martin (1995) definem essas dificuldades de aprendizagem como desordens que acontecem no processo de aquisição de aprendizagem de um modo geral, não necessariamente como conseqüência das causas endógenas/orgânicas, mas, sim, provenientes de fatores variados que podem ser mais facilmente removidos ou eliminados. Ainda assim, esses processos correspondem a uma dificuldade funcional das habilidades cognitivas, que obedecem a um comando cerebral que se mostra em atraso quando comparado com a maioria de crianças dessa faixa etária, o que as deixa em desvantagem numa avaliação que não valorize o seu próprio ritmo. Ao mesmo tempo, em vez de serem apartadas de seu ambiente, elas necessitam, ao contrário, de uma participação e de um envolvimento maior para superar seus próprios limites, onde a auto-estima, que normalmente se machuca nas frustrações, precisa ser o suporte para sua mudança.

Na avaliação psicológica, as crianças se situaram, em geral, na classificação intelectual correspondente à média. Do total, 122 crianças apresentavam dificuldades emocionais, quase todas de fundo psicossocial (resultantes das interações ambientais e familiares), destacando-se: desestruturação familiar, insegurança, retraimento, agressividade. Na avaliação fonoaudiológica, das 159 crianças 41 apresentavam alguma alteração na leitura, na escrita ou na elaboração de textos, além de outras 17 , com predominância de dificuldades relacionadas à audição.

Os resultados levantados no Cemada mostram a necessidade de atuação multidisciplinar na compreensão e inserção de crianças que não acompanham o ritmo comum do ensino. Esse levantamento possibilitou, também, notar os aperfeiçoamentos que se fazem necessários nesse serviço, em dois níveis: no encaminhamento das crianças pelas escolas (porque a demanda é muito superior à capacidade de atendimento) e na prevenção (uma vez que a maioria dos problemas mereceria uma intervenção anterior ao estabelecimento do quadro). Acredita-se, entretanto, que esses dois aspectos estão interligados e denunciam a ausência do psicólogo escolar, que poderia atuar no ambiente natural da criança (na escola e junto à família) tanto na prevenção como na solicitação de avaliações específicas, realizando as orientações à escola e à família antes que a criança sofresse frustrações e desencantos que corrompessem sua auto-estima e determinassem sua marginalização. A prevenção, antes de ser um procedimento aplicável, "é conseqüência de uma conjunção social e política referendada num compromisso com a cidadania em seus mais variados aspectos (Belisário, 1992).

O psicólogo escolar precisa, portanto, articular os diversos ângulos de uma pluralidade de vozes e estilos que compõem o mundo da criança. Como afirma Morin (1995), o problema não está em que cada um perca sua competência, mas em que a desenvolva suficientemente para articulá-la com outras competências (disciplinas e conhecimentos) que, ligadas numa cadeia, formariam o anel completo e dinâmico, o anel do conhecimento.

Concluindo, percebe-se que há uma carência de definição de modelos de atuação do psicólogo escolar no Brasil, o que dificulta a identificação de habilidades na prática para que ele possa atender às exigências diversas no contexto de relações que se estabelecem em torno da criança (Del Prette e Del Prette, 1996). Esse problema não pode ser resolvido sem uma ampliação no atual espaço de ação desse profissional. É tempo de rever os impedimentos que obscurecem sua possibilidade de exercer os trabalhos sociais que lhe cabem, sua ausência na educação pública, sua limitada participação no ensino particular.

A escola é um espaço vital para a promoção da saúde e é preciso construir uma prática voltada para
Há uma carência de definição de modelos de atuação do psicólogo escolar no Brasil, o que dificulta a identificação de habilidades na prática para que ele possa atender às exigências diversas no contexto de relações que se estabelecem em torno da criança. 
a interlocução com outras áreas de conhecimento, para articular com outras competências uma ética de transformação social e um novo conceito de saúde, conforme aponta Branco (1999): "A saúde envolve a eliminação da fome, da miséria, da ignorância e de qualquer forma de opressão. O compromisso do psicólogo só pode ser com a mudança social" (p. 34). Cabe-lhe pesquisar, intervir, planejar e promover a saúde mental no contexto escolar que, obviamente, não se aparta do restante do ambiente que envolve o aluno. O duplo desafio que se ergue diante do psicólogo escolar, o de afirmar-se no seu espaço de trabalho para lidar com os aspectos psicológicos e educacionais que envolvem o desenvolvimento infantil e sua adaptação no mundo, faz parte do seu campo de atuação.

"A saúde envolve a eliminação da fome,

da miséria, da

ignorância e de qualquer forma de opressão".

Branco
No Brasil, contamos com leis criteriosas que defendem os direitos das crianças, mas que não são regulamentadas e, portanto, não funcionam. Problemas reais como repetência ou inclusão de alunos são resolvidos com determinações teóricas que não oferecem respaldo estrutural para atender às exigências práticas que acompanham projetos utópicos. Profissionais competentes ficam "ilhados" por idéias que não encontram caminhos correspondentes aos desejos de mudanças. O reconhecimento de estruturas próprias de cada localidade não pode ser ignorado na imposição de modelos prontos, em lugar da estimulação à criação de soluções adequadas a cada situação. O atendimento psicológico na escola precisa antever as dificuldades para resolvê-las, mas também precisa oferecer suporte às necessidades especiais para as quais o psicólogo deve estar capacitado. O movimento contra a patologização do erro, visando a encarar nele um degrau e não um final de caminho, afasta a criança da tendência de responsabilizá-la pelo fracasso do processo de ensino, mas o atendimento a patologias também pode ser necessário, justamente para oferecer recursos de adaptação ou reabilitação, desde que não seja o alvo limitado de ação do profissional de uma instituição. As controvérsias existem e precisam ser discutidas. São elas que tornam cada chegada uma nova partida, um espaço a mais a pesquisar. A existência de conflitos pode ser justamente o fator que torna a presença do psicólogo necessária em ambiente multidisciplinares e, mais ainda na escola, onde se constrói uma nação.

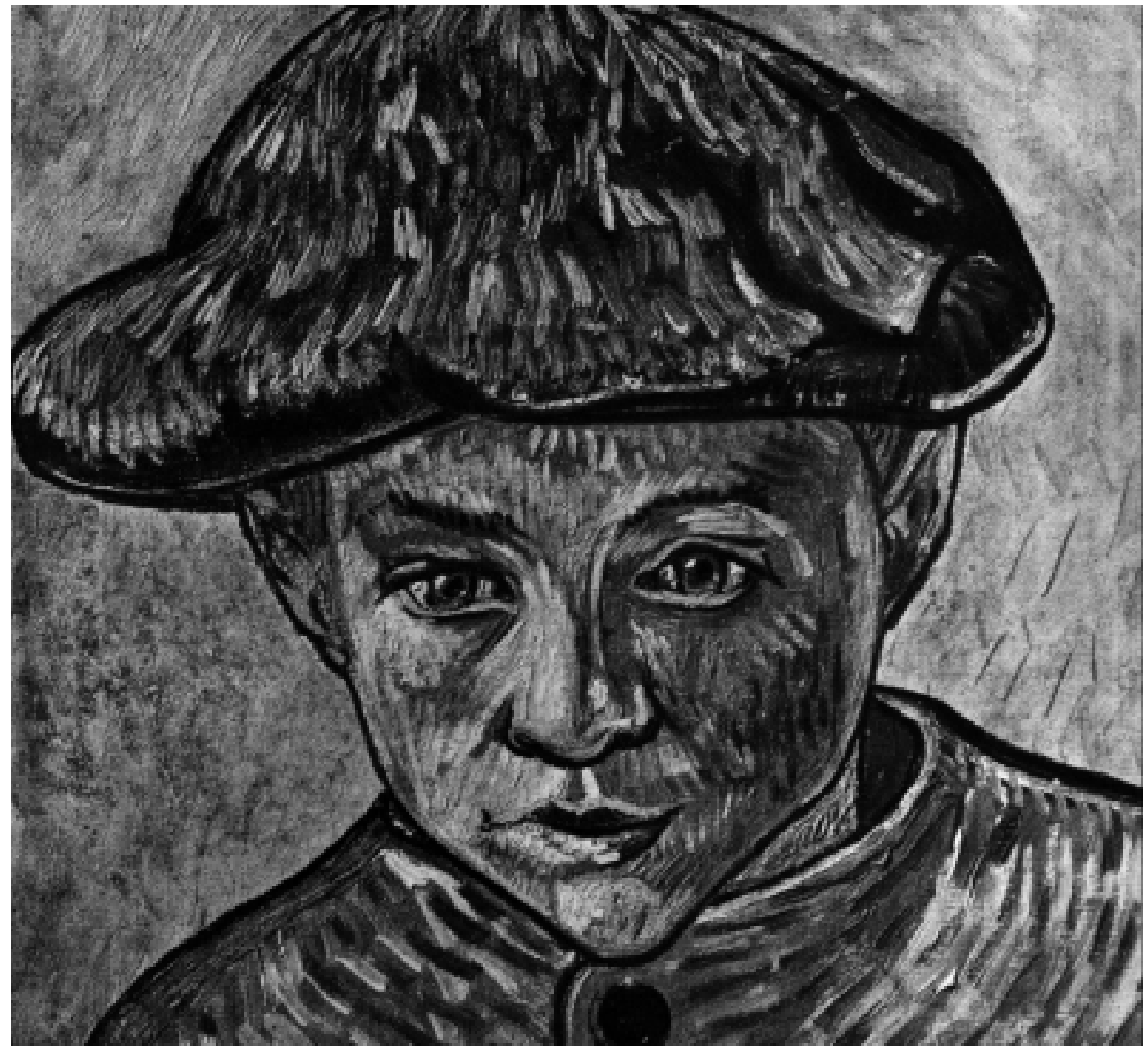


ABRAPEE. (1991). Constituição e Estatuto da Associação Brasileira de Psicologia Escolar e Educacional, Campinas.

Almeida, L., Guzzo, R. S. L. (1992). A relação psicologia e educação: perspectiva histórica do seu âmbito e evolução. Estudos de Psicologia, 9 (3), 117-131

Andaló, C. S. de A. (1984). O papel do Psicólogo Escolar. Psicologia: Ciência e Profissão, 4 (1), 43-46.

Andreazzi, L., Jacarini, C.S., Prigenzi, L., (1994). Criatividade e conduta participativa em sala de aula. Resumos - II Congreso Nacional de Pré-Escolar. Campinas: PUC-Campinas.

Bassedas, E., Huguet, T., Marrodan, M., Olivan, M., Planas, M. Rossel, M., Seguer, M. e Vilella, M. (1996). Intervenção educativa e diagnóstico psicopedagógico. Porto Alegre: Artes Médicas.

Batsche, G., Knoff, H. (1995). Best practices in linking assessment to intervention. In: A. Thomas e J. Grimes, ed. Best practices in school psychology. $3 \underline{a}$ ed. Washington: NASP.

Belisário, M. de A. (1992) Saúde Mental. Em R. H. de F. Campos; G.A. V. da Silva; M. de A. Belisário; M. H. C. Moreira; C. R. Darwin E. D. Gontijo; J. M. Pinto. Psicologia: possíveis olhares outros fazeres. Belo Horizonte: CRP, 4a Região.

Brambilla, L. H. (1997). Adaptação da Bacil: Bateria de avaliação dos comportamentos iniciais de leitura. Dissertação de Mestrado. Campinas: PUC-Campinas.

Branco, M. T. (1999) Psico-higiene e Psicologia institucional, $3^{a}$ ed., Porto Alegre: Artes Médicas.

Bronfenbrenner, U. (1996). A ecologia do desenvolvimento humano: experimentos naturais e planejados. Porto Alegre: Artes Médicas.

EFA (Eduaction for all). (1990) Reunião Mundial naTailândia. Brasília: MEC.

Demo, P. (1993) Desafios modernos na educação. Petrópolis: Vozes.

Del Prette, Z. A. P., Del Prette, A. (1996) Habilidades envolvidas na atuação do psicólogo escolar e educacional. IN S. Weschsler (org.). Psicologia escolar: pesquisa, formação e prática. Campinas: Alínea.

Dimenstein, G. (1994). O cidadão de papel: a infância, a adolescência e os direitos humanos no Brasil. São Paulo: Ática.

Durlak, J. (1998). A successful prevention programs for children and adolescents. New York: Plenum.

Eysenck, H.J. \& Eysenck, M.W. (1985). Personality and individual differences: a natural science approach. London: Plenum.

Fergays, D. G.(1982). Environmental influences and strategies in primary prevention. New England: Vermont.

Gridley, B.; Mucha, L.; Hatfield, B. Best practices in preschoo screening. In: A. Thomas e J. Grimes, ed. (1995). Best practices in school psychology. $3^{\mathrm{a}} \mathrm{ed}$. Washington: NASP.

Guzzo, R. S. L. (1990). Dificuldade de aprendizagem: uma contribuição ao diagnóstico psicoeducacional. Relatório do CNPQ.

Guzzo, R. S. L. e Weschler, S. M.(1993). O psicólogo escolar no Brasil - cap. III, in: Guzzo, R. S. L. e Weschler, S. M., Psicologia Escolar: Padrões e práticas em países de língua espanhola e portuguesa. Campinas: Átomo.

Hightower, D., Johnson, D., Haffey, W. (1995). Best practices in adopting a prevention program. In: A. Thomas e J. Grimes ed. Best Practices in School Psychology. 3 a ed. Washington: NASDP.

Knoff, H. (1995). Best practices in personality assessment. In: A Thomas e J. Grimes ed. Best practices in school psychology. $3^{\underline{a}}$ ed. Washington: NASDP.

Machado, A. M., Souza, M. P. R. (orgs.). (1997). Psicologia escolar: em busca de novos rumos. São Paulo: Casa do Psicólogo.

Magnusson, D., Kinteberg, B., Sattin, H. (1994). Juvenile and persistent offenders: behavioral and psychological characteristica. In R. D. Ketterlinus, Lamb, J. ed. Adolescent problem behaviors. Hillsdale. NJ: Erlbaum.

Marquesi, A. M. Souza, M. P. R. (orgs.) (1995) Da terminologia do distúrbio às necessidades especiais. Em: J. Palacios; A. Marques (orgs). Desenvolvimento psicológico e educação: necessidades educativas especiais e aprendizagem escolar. Porto Alegre: Artes Médicas.

Morin, E. (1998). Ciência com consciência. Tradução de Maria D. Alexandre e Maria Alice Dória. Rio de Janeiro: Bertrand Brasil.

Pfromm Netto, S. (1995). Editorial Informativo ABRAPEE, 3 (6), 1995, 1.

Rey, F. G. (1993). Personalidad, salud y modo de vida. Mexico: Unan Iztacala.

Ribeiro do Valle, L. E. L. (2000). Alfabetização: dificuldades observadas em crianças da rede municipal de Poços de Caldas em avaliação multidisciplinar. Manuscrito IPF, PUC, Campinas.

Ribeiro do Valle, L. E. L. (2001). Desenvolvimento sócio-emocional da criança na educação infantil: uma perspectiva preventiva. Dissertação de Mestrado. PUC, Campinas.

SAEB (Sistema Nacional de Avaliação da Educação Básica). Censo 1999. Brasília: INEP.

Wise, P. S. (1995). Best practices in communicating with parents. In: A. Thomas e J. Grimes. Best practices in school psychology. 3a ed. Washington: NASP

Witter, G. P. et alii (1992). Atuação do psicólogo escolar e educacional no Brasil: perspectivas através de textos (1980-1992) Cap. 2, in: CPF, Psicólogo brasileiro: construção de novos espações, Campinas, Átomo: 23053.

\section{Referências bibliográficas}

